Plastino, M.R.; Pereira, D.C.; Maia, M.G.M.; Lopes, D.A. Ecoturismo, cultura e comunidades: reflexões sobre o entorno da RPPN Santuário do Caraça (MG). Revista Brasileira de Ecoturismo,

\title{
Ecoturismo, cultura e comunidades: reflexões sobre o entorno da RPPN Santuário do Caraça (MG)
}

\author{
Marina Ramos Plastino, Denise de Castro Pereira, \\ Marlete da Glória Martins Maia, Danielle Alves Lopes
}

\begin{abstract}
RESUMO
O objetivo deste artigo é refletir sobre perspectivas para o desenvolvimento local por meio de iniciativas de preservação cultural associadas ao ecoturismo em quatro comunidades do entorno da RPPN Santuário do Caraça (MG). Essa região é marcada por áreas protegidas pressionadas pelo adensamento urbano e por intensivas atividades de mineração, o que expõe tais comunidades a uma gama de problemas socioambientais. A pesquisa realizada por meio do diagnóstico rápido participativo (DRP) demonstrou que as comunidades identificam, mas nem sempre valorizam suas tradições, seu modo de vida tipicamente rural, o manejo dos recursos naturais, os rituais religiosos, a beleza paisagística e os sítios históricos locais como atrativos turísticos. Essa descoberta induziu a proposição de ações em rede social para promover discussões sobre as potencialidades locais, considerando o planejamento turístico participativo como estratégia para construir soluções comunitárias.
\end{abstract}

PALAVRAS-CHAVE: Ecoturismo; Comunidades; Rede Socioambiental.

\section{Ecotourism, culture and communities: reflections about Caraça Sanctuary PRNP surrounding, MG, Brazil}

\section{ABSTRACT}

The aim of this paper is to discuss prospects for local development through cultural preservation initiatives related to ecotourism in four communities surrounding the Caraça Sanctuary PRNP (MG, Brazil). This region is marked by protected areas compressed by urban densification and intensive mining activity, which expose these communities to a range of socio-environmental problems. The research conducted through participatory rapid appraisals (PRA) showed that communities identify, but not always value their traditions, their typically rural way of life, the management of natural resources, religious rituals, the natural beauty and local historic sites as tourist attractions. This discovery led to actions being proposed in the social net to promote discussions on potential sites, considering the participatory tourism planning as a strategy to build community solutions.

KEYWORDS: Ecotourism; Communities; Socio-environmental Net. 
Ecoturismo, cultura e comunidades: reflexões sobre o entorno da RPPN Santuário do Caraça (MG).

\section{Introdução}

Em determinados contextos sociais, o desenvolvimento de base local se torna ameaçado pela economia predominante na região. As regiões intensivas em atividades mineradoras e industriais, assim como os grandes centros urbanos, são apontadas como clássicos exemplos de tais ameaças. Paradoxalmente, em ambientes de mineração destacam-se práticas de proteção e conservação ambiental, em especial, por meio de reservas particulares de patrimônio natural, as RPPNs, instituídas por força da lei, como medida de compensação por danos ambientais.

Em Minas Gerais, no contexto do Quadrilátero Ferrífero e da Região Metropolitana de Belo Horizonte, encontra-se a Área de Proteção Ambiental Sul (APA SUL RM$\mathrm{BH})$, composta por mais de duas dezenas de unidades de conservação. Sua localização a caracteriza como uma região intensiva em mineração e metalurgia. Conforme diversas fontes de pesquisas, institucionais e científicas, a complexidade dos múltiplos usos dos recursos ambientais, neste território, colocam a preservação cultural das comunidades urbanas e periurbanas que nele se localizam em situação de vulnerabilidade. Ao mesmo tempo, a conservação ambiental e, com ela, o ecoturismo se tornam pressionados na medida em que se configuram diferentes formas de uso do solo, seja para empreendimentos imobiliários e industriais ou, especificamente, para a extração mineral.

O reconhecimento de traços de situações de ameaças e vulnerabilidade socioambiental, as áreas de degradação ambiental e a exaustão de recursos naturais colocam em evidência movimentos sociais e estatais a favor da preservação ambiental e da sustentação de unidades de conservação. No seio de tais iniciativas, recolocam-se as questões associadas às estratégias de desenvolvimento social e econômico e o enfretamento das polêmicas entre atores e interesses distintos. No caso da APA SUL $\mathrm{RMBH}$, as comunidades locais sofrem diretamente os impactos dos avanços da economia mundial e vivenciam a intensificação das atividades minerárias consideradas prioritárias como motoras do desenvolvimento do estado. Essas afirmações derivamse, entre outras fontes, dos esforços de pesquisa e extensão universitária, realizados por ocasião da implementação do projeto estruturante da Rede Socioambiental APA SUL RMBH, considerada o primeiro nodo de uma Rede de Pesquisa e Extensão Socioambiental em Regiões Mínero-metalúrgicas ${ }^{1}$.

A partir de debates sobre perspectivas do desenvolvimento local e alternativas socioeconômicas para comunidades no entorno de unidades de conservação ambiental e, ao mesmo tempo, de empreendimentos mineradores, configura-se como campo de interesse, neste artigo, a conexão entre o ecoturismo e a preservação cultural como meio para qualificar e recuperar valores da vida cotidiana.

As quatro comunidades e a região objeto de estudo neste trabalho situam-se no entorno da Reserva Particular de Patrimônio Natural Santuário do Caraça, localizada em territórios dos municípios de Catas Altas e Santa Bárbara (MG). Essas localidades encontram-se entremeadas a empreendimentos mineradores de ferro e ouro, de 
propriedade de empresas como Vale e AngloGold-Ashanti. Ademais, trata-se de uma região com vastas extensões de monocultura de eucalipto e de extração de minerais não-metálicos, especialmente para a construção civil. Essa realidade, como mencionado, suscita a existência de áreas protegidas entre as quais se destacam, além do Caraça, também tombado como patrimônio histórico-cultural, as RPPNs de propriedade de mineradoras como as da Vale, mas que não são abertas à visitação pública. Nessas comunidades identifica-se a diversidade de elementos constitutivos da cultura local, entre os quais se destacam ritos, cerimônias, tradições religiosas, patrimônios arquitetônicos, atrativos naturais, traços da história ambiental da mineração em Minas Gerais, além de uma gama de atividades de produção para a subsistência, principalmente, de agropecuária familiar, detalhadas no decorrer deste artigo.

A par de tal complexo de interações regionais e da potencialidade para a transformação socioambiental, neste artigo, busca-se refletir sobre a pertinência de consolidação de uma rede local como espaço para o planejamento participativo do ecoturismo de base comunitária visando contribuir com o desenvolvimento local.

Com este propósito, em primeiro lugar o artigo apresenta uma síntese da metodologia de pesquisa adotada. A segunda seção, de resultados e discussão, destaca referências sobre práticas de ecoturismo, ressaltando relações com comunidades tradicionais (e rurais), as conexões entre as tradições culturais, o ecoturismo comunitário e planejamento participativo. Em seguida, os resultados da pesquisa são sintetizados para caracterizar tais comunidades para que se possa, finalmente, concluir sobre a pertinência da rede local como oportunidade qualificada para a discussão e a construção de planos e projetos para buscar a permanência dos moradores em suas comunidades.

\section{A metodologia da pesquisa}

A pesquisa realizada entre 2007 e 2009, em interface com a Extensão Universitária (PEREIRA et al., 2010), adotou um composto metodológico que combinou técnicas de levantamento de dados secundários, análise documental e de pesquisa social de caráter participativo e comunitário, construídas a partir de Brose (2001), Minayo (2004), Thiollent (2004) e Rocha $(2003,2006)$.

A preparação da equipe, composta por três professores, quatro bolsistas de apoio técnico, nove de iniciação científica e duas colaboradoras, iniciou-se com embasamento teórico sobre o contexto regional e a captação de dados secundários sobre a região objeto de estudo. Buscou-se conhecer suas respectivas características socioambientais, econômicas e políticas. Paralelamente, deu-se início a uma fase exploratória, em campo, com o intuito de se conhecer as populações locais, estabelecer os primeiros contatos e apoios institucionais, detectar resistências e avaliar a viabilidade de intervenções locais. Essa fase foi fundamental para a seleção das comunidades objetos da pesquisa, descritas nesse artigo.

Foram selecionadas, então, quatro comunidades localizadas em Santa Bárbara 
(MG) - Conceição do Rio Acima, Galego, Santana do Morro e Sumidouro - nas quais se desenvolveu o Diagnóstico Rápido Participativo (DRP). Dentre a diversidade de técnicas adotadas, destacaram-se: a observação participante com registros fotográficos; os mapas mentais digitalizados; a história oral; as entrevistas livres e semiestruturadas; a linha do tempo; as caminhadas transversais; as dinâmicas de grupo como recursos para desinibição e conhecimento entre moradores e pesquisadores.

Pode-se considerar que o DRP oferece alternativas eficazes para o estudo de problemas específicos de uma localidade, possibilitando o autoconhecimento e o empoderamento da comunidade (BROSE, 2001). Nesta pesquisa, em particular, o DRP foi aplicado como recurso associado no processo de formação de agentes de desenvolvimento local (ADL), que se caracterizava como objetivo específico da pesquisaextensionista. Essa possibilidade se concretizava na medida em que, a partir da valorização rápida e funcional dos saberes locais, analisavam-se as dificuldades e potencialidades da população com o interesse deliberado, coletivamente, de criar oportunidades de busca e consolidação de estratégias para a solução de problemas e conflitos socioambientais. Ações de mobilização social, segundo Toro e Werneck (2005), foram constantes e significativas durante a pesquisa, tendo em vista o perfil das comunidades, tipicamente periurbanas ou que, pela aproximação, mesclam traços rurais com urbanos (SANTOS, 2003) e demonstram, relativamente, pouca experiência de participação em projetos coletivos em busca do desenvolvimento local.

Conforme as orientações metodológicas os processos de devolução dos dados às comunidades foram intensivos. Em certos momentos, no entanto, foi possível registrar o distanciamento entre a equipe da pesquisa e membros das comunidades. A distância física entre tais comunidades e a universidade, foi considerada como elemento dificultador dos deslocamentos da equipe causando ausências prolongadas e, em alguns momentos, morosidade nos trabalhos.

A culminância do processo de pesquisa ocorreu com a realização do I Fórum Local das Comunidades do Entorno da RPPN Santuário do Caraça, em setembro de 2009. Nesta oportunidade, encontraram-se membros das quatro comunidades pesquisadas, com representantes dos segmentos de governo local, de órgãos ambientais estatais, de empresas e entidades da sociedade civil, com intuito de se configurar a rede local e de demonstrar a conexão com a rede regional, ou seja, a Rede Socioambiental APA SUL RMBH.

Vale registrar que, conforme o objetivo do projeto de estruturar a rede socioambiental em regiões mínero-metalúrgicas, outras iniciativas de pesquisa ocorriam paralelamente. Entre elas destacam-se: a pesquisa com os outros dois núcleos comunitários no entorno do Parque Estadual Serra do Rola-Moça (Belo Horizonte, Nova Lima, Brumadinho, Ibirité) e do Parque Municipal das Mangabeiras (Belo Horizonte) com seus respectivos DRPs, fóruns e redes locais; a realização de três seminários setoriais, organizados com os segmentos de governo local, de empresas e entidades da sociedade civil, para constituição da rede; e ao final, o II Fórum da Rede Socioambiental APA SUL RMBH, em dezembro de 2009. 


\section{Resultados e Discussão}

Tendo em vista o objetivo de refletir sobre a pertinência de consolidação de uma rede local como espaço para o planejamento participativo do ecoturismo de base comunitária visando contribuir com o desenvolvimento local, esta seção apresenta reflexões sobre as bases conceituais que podem sustentar tal proposta.

\section{Desenvolvimento local, ecoturismo e cultura: dimensões conceituais sobre a realidade comunitária}

A adoção de referências conceituais e empíricas relativas ao desenvolvimento local abarca uma diversidade de dimensões associadas às múltiplas perspectivas de tratamento do tema, aí incluídas as variações políticas e ideológicas que o perpassam. O ponto de partida orientador da reflexão associa-se à sistematização que incorpora elementos sociais, econômicos e ambientais, visando à qualidade de vida de comunidades em um dado território, independentemente da circunscrição a territórios urbanos ou rurais. A concepção a seguir, formulada a propósito de orientar iniciativas de planejamento local e municipal sustentável, demonstra a amplitude e a complexidade das questões centrais na condução de princípios e interações que mediam políticas, projetos e decisões, sejam elas de caráter estatal ou comunitárias.

Desenvolvimento local é um processo endógeno registrado em pequenas unidades territoriais e agrupamentos humanos capaz de promover o dinamismo econômico e a melhoria da qualidade de vida da população. Representa uma singular transformação nas bases econômicas e na organização social em nível local, resultante da mobilização das energias da sociedade, explorando as suas capacidades e potencialidades específicas. Para ser um processo consistente e sustentável, o desenvolvimento deve elevar as oportunidades sociais e a viabilidade e competitividade da economia local, aumentando a renda e as formas de riqueza, ao mesmo tempo em que assegura a conservação dos recursos naturais. (BUARQUE, 1999, p. 8. Ênfases no original).

Esta concepção nos remete à busca de elementos estimuladores de iniciativas de renovação de práticas sociais, capazes de sensibilizar atores para a quebra de determinadas tradições, no sentido proposto por Boaventura de Souza Santos (2005), que considera o desenvolvimento local como um espaço de experimentação. Ao mesmo tempo, remete às possibilidades de movimentos sociais fazerem frente, sobretudo, às desigualdades geradas por iniciativas transformadoras decorrentes da esfera do mercado, ou seja, de buscarem alternativas aos impactos negativos na mesma medida em que se pode potencializar impactos positivos, coerentes com interesses e tradições locais. Nesse sentido, o poder local assume o protagonismo, como força política, na tentativa de (re)construção do sentido do lugar, a partir de ações que busquem ampliar o sentimento de pertencimento ao território. Em acepção contrária às tendên- 
Ecoturismo, cultura e comunidades: reflexões sobre o entorno da RPPN Santuário do Caraça (MG).

cias homogeneizadoras, essa perspectiva prioriza histórias, valores e símbolos escoIhidos pela comunidade como referências socioculturais.

As estratégias e práticas do desenvolvimento local tratam, especialmente, de promover capacidades para que comunidades locais preservem sua própria sustentabilidade e a da natureza (SANTOS, 2005), considerando-se ainda que o local traz significados especiais sobre ser um espaço onde se produzem e solucionam conflitos, onde se realizam alianças interinstitucionais e entre sujeitos da ação cotidiana; bem como um espaço para a viabilização e a democratização de políticas públicas.

No que se refere à realidade social, Carvalho (2004) também destaca a importância de se promover o desenvolvimento não apenas do ponto de vista econômico, mas do ponto de vista das pessoas e do ambiente. Tal perspectiva conduz ao argumento de que a conscientização e, em consequência, a mobilização, da sociedade promovem estímulos às reivindicações de direitos e o fortalecimento da cidadania, como modo de se fazer avançar sobre a luta pela mera emancipação econômica. Tornase essencial nesse processo, o aprendizado de ações participativas - capazes de aproximar a decisão do espaço de ação do cidadão (DOWBOR, 2008) - e, portanto, exige do sujeito, agente do desenvolvimento local, o conhecimento amplificado sobre sua realidade, bem como a compreensão e o aprendizado das políticas públicas e das práticas democratizantes ou participativas para viabilizá-las. Como se destaca, "o desenvolvimento local requer sempre alguma forma de mobilização e iniciativas dos atores locais em torno de um projeto coletivo" (BUARQUE, 1999)

Por um lado, essas questões remetem à necessária presença do Estado na sustentação de tais políticas. Por outro, fortalecem os discursos e as iniciativas de articulações intersetoriais, não só no contexto local, mas em escalas distintas, capazes de envolver iniciativas públicas, privadas e da sociedade civil, em prol de projetos de interesses comunitários e/ou municipais. Uma dimensão fundante de tais iniciativas deve ser o sentimento de pertencimento ao local, expresso pelos sujeitos e que deve cumprir o papel de dar sustentação às formas de sociabilidade geradas nas configurações territoriais ou organizacionais que se estabelecem. Especialmente, destacam-se as redes capazes de consolidar ações coletivas e geradoras de alternativas para 0 fortalecimento das comunidades.

O fortalecimento de comunidades locais e de municípios com dificuldades de equacionamento entre demandas e condições de solucioná-las, frequentemente, envolve debates sobre a democratização de instâncias públicas de decisão; promoção do acesso a mercados (escala, controle de qualidade, logística, etc.); elaboração coletiva de programas de desenvolvimento local endógeno; promoção da gestão de políticas integradas; manutenção da governabilidade sobre o processo; articulação de atores e produção de alterações na economia local; e, compreensão das articulações setoriais e territoriais (CALDAS; VAZ; MARTINS, 2005).

$\mathrm{Na}$ concepção do desenvolvimento local, tais dificuldades podem se transformar em oportunidades na medida em que solucioná-las ou restringir seus impactos 
implicar em enfrentar os desafios construindo novas institucionalidades, promovendo regulações sociais coerentes com a perspectiva da sustentabilidade, renovando tecnologicamente as formas de usos de recursos e as práticas sociais e sendo indutor de ações governamentais.

As redes sociais, como arranjos socioinstitucionais, podem tomá-las como estímulos ou desafios, na medida em que, tratá-las no processo participativo de construção das opções comunitárias para o desenvolvimento local, pode significar a antecipação de conflitos e a constituição de fóruns de acomodação de interesses distintos. Noutras palavras, pode suscitar a solução integradora de necessidades dos diferentes atores, por vias que compatibilizem a consistência de soluções para a vida econômica com a conservação ambiental e as tradições do modo de vida simples, próximo à natureza, com tecnologias sustentáveis.

Neste sentido, destacam-se os espaços democráticos participativos para o planejamento e gestão a partir do local; as orientações e as práticas da economia solidária a partir de atividades produtivas de pequeno porte e possíveis arranjos interempresas para se constituírem serviços, produtos e sistemas de apoio territorializados; e não menos importante, a valorização das práticas de capacitação de agentes de desenvolvimento local, em busca de processos de aprendizagem compartilhada (RITS, 2004).

\section{Tradições culturais, ecoturismo comunitário e planejamento participativo}

A associação do desenvolvimento local a regiões onde se concentram comunidades tradicionais, áreas nativas e de conservação ambiental não se apresenta como novidade, mas continua desencadeando questionamentos em torno das opções a serem feitas. As atividades extrativistas da cadeia vegetal e o ecoturismo, frequentemente, são apresentados como soluções primárias exemplares para a sustentação de povos, populações e comunidades tradicionais. O que as define como tal, segundo o Decreto 6.040 , Art. $3^{\circ}$, de 07 de fevereiro de 2007, é o fato de serem reconhecidas como grupos culturalmente diferenciados, que possuem formas próprias de organização social, protegem, ocupam, usam territórios e recursos naturais como condição para sua reprodução cultural, social, religiosa, ancestral e econômica, utilizando conhecimentos, inovações e práticas gerados e transmitidos pela tradição.

Tais especificidades circunscrevem condições restritivas à identificação ou à autoidentificação das comunidades tradicionais, mas permitem ampliar seus limites para a percepção de traços de tradições comunitárias ancestrais em distintas formações populacionais ou povoados, mesmo que convivendo de modo mais intenso com o modo de vida urbano, com o mundo moderno, incorporando hábitos de consumo de bens manufaturados, descaracterizando seu modo de vida. No entanto, de modo geral, encontra-se grande porção da biodiversidade onde, há várias gerações, residem comunidades que adotam práticas tradicionais de uso e manejo dos recursos naturais como meio de sobrevivência (PRIMACK; RODRIGUES, 2001). 
Ecoturismo, cultura e comunidades: reflexões sobre o entorno da RPPN Santuário do Caraça (MG).

As posturas paradoxais relativas à conservação ambiental e à vida em comunidade destacam, de um lado, a existência da comunidade como destruidora da diversidade biológica e de outro, como nobre selvagem, que prioriza intervenções mínimas no ambiente, com tradições e modos de vida harmônicos. Entre essas, surge a concepção intermediária, a respeito do quanto as mudanças sociais promovem diferenças entre as gerações e afetam suas relações com a natureza.

No contexto destes debates, a criação de unidades de conservação (UCs), como medida legal e de ordem estatal, por vezes adotou medidas que ignoravam os direitos e práticas tradicionais das populações adjacentes, semelhante aos abusos colonialistas de épocas passadas. Cox e Elmqvist (1993) citadas por Primack e Rodrigues (2001) definem tais medidas como ecocolonialistas. Estas, de modo geral, acarretam conflitos com as populações residentes em seu entorno, quando estas se vêem desprovidas do acesso aos recursos naturais dos quais sempre usufruíram ou até mesmo protegeram. Movidas por um sentimento de não-pertença, as comunidades podem promover práticas ilegais e destrutivas ao ambiente. Por outro lado, essas populações, podem ser consideradas principais guardiãs de seu patrimônio, visto que detém conhecimentos etnográficos e das representações sociais relativas à natureza. (RUSSO, 2005). Diversos estudos sobre etnobiologia salientam a sua importância no intuito de se ampliar o conhecimento sobre o uso e o manejo dos recursos naturais, corroborando a formulação de práticas conservacionistas, articuladas e vinculadas a benefícios sociais comunitários (BRANDON, 2002; BEGOSSI et al., 2006).

Essa discussão reforça os argumentos sobre a adequação das práticas de ecoturismo em UCs e em seu entorno, exatamente, na medida em que valoriza a relação com a vida prática das comunidades (mesmo que elas sejam oriundas de experiências urbanas ou as UCs tenham fronteiras com áreas urbanas). Sua denominação é associada ao

deslocamento de pessoas a espaços naturais delimitados e protegidos pelo Estado ou controlados em parceria com associações locais e ONGs. Pressupõe sempre uma utilização controlada da área com o planejamento de uso sustentável de seus recursos naturais e culturais, por meio de estudos de impacto ambiental, estimativas da capacidade de carga e suporte do local, monitoramento e avaliação constantes, como plano de manejo e sistema de gestão responsável (BENI, 2004, p. 427).

Considerado como uma atividade planejada e monitorada por medidas regulatórias e com a participação do Estado em seu gerenciamento, o ecoturismo pode constituir-se como gerador de alternativas de renda para as populações do entorno das UCs, na medida em que soluções integradoras ou de parcerias se estabelecerem. Vale ressaltar que a distinção entre o ecoturismo e o turismo ecológico, que é marcado pela espontaneidade da exploração turística, por não ser acompanhado por políticas que possam assegurar a conservação dos recursos naturais, faz sentido quando se trata da relação entre comunidades e APA - Área de Proteção Ambiental. O seg- 
mento de turismo ecológico é compreendido como o

Deslocamento de pessoas para espaços naturais, com ou sem equipamentos receptivos, motivados pelo desejo/necessidade de fruição da natureza, observação passiva da flora, da fauna, da paisagem e dos aspectos cênicos do entorno. Somam-se a essas atividades o exercício eventual da caça e pesca e excursões programadas para pontos geográficos de interesse turístico: rios, ilhas, montanhas e chapadas, grutas e cavernas, minas e jazidas. Em todos esses casos, ainda que haja uma preocupação de educação e conscientização ambiental, a característica dominante é uma maior flexibilização ou inexistência de restrições rígidas e limites de utilização do espaço visitado (BENI, 2004, p. 127).

O modo como se definem essas práticas turísticas endossam a sua livre ocorrência em áreas de proteção ambiental. No Brasil, segundo Beni (2004) tais termos são comumente confundidos e as diretrizes do ecoturismo ainda podem ser consideradas pouco aplicadas, na medida em que as UCs não desenvolverem políticas integradas estratégicas para seu uso e ocupação voltados especificamente para o turismo.

Tais considerações fazem sentido, no contexto da vida moderna, pois o turismo se configura como ato indulgente, por proporcionar aos indivíduos, experiências fora do seu cotidiano, distintas do mundo real e do trabalho. Ao mesmo tempo é mercadoria, para suprir as necessidades da sociedade de consumo. Como outros produtos, a viagem é dotada de símbolos, ícones e devaneios criados por quem a compra e pratica. Ainda assim, criando contradições, o turismo pode apresentar-se como alternativa econômica para localidades excessivamente exploradas pelos setores primários e secundários, podendo ser considerada uma atividade estratégica para a preservação e manutenção dos patrimônios materiais e imateriais, bem como tática para a conservação dos recursos naturais (AKEHURST, 2001). O ecoturismo, por sua vez, cresceu significativamente nos últimos tempos, pois possibilita aos sujeitos sociais - sobretudo do universo urbano - estabelecerem contatos com o meio natural. Tal segmento apresenta como mote a possibilidade de usufruto da biodiversidade, o que demanda reflexões e métodos de ação demarcados por políticas públicas, especialmente, em educação e conservação ambiental, já incorporando as orientações da Rio 92 a respeito da correlação entre turismo e meio ambiente.

Nessa perspectiva, desenvolvem-se os estudos acerca da ética turística contemplando a conservação dos recursos naturais e a inclusão social. É a partir dessa premissa que o turismo se materializa como alternativa pra o desenvolvimento local e sustentado. Com efeito, a fragilidade dos recursos naturais em muitos casos não suporta o alto fluxo de visitantes e de veículos automotivos, que geram comprometimen- 
Ecoturismo, cultura e comunidades: reflexões sobre o entorno da RPPN Santuário do Caraça (MG).

to da paisagem, da topografia, dos recursos florísticos, faunísticos e hídricos.

A atividade turística em locais naturais deve, portanto, ser dotada de premissas e diretrizes que permitam a conservação sustentada da biodiversidade, bem como se apresente como uma benéfica alternativa econômica para as comunidades, possibilitando um cenário favorável ao combate às desigualdades sociais.

As proposições para que o ecoturismo seja um segmento capaz de contribuir para desenvolver uma localidade, defendem o planejamento coletivo, tendo os sujeitos locais como os principais gestores e articuladores da atividade. Caso contrário, a mesma poderá não se estabelecer como uma alternativa econômica para a comunidade, mas sim, configurar-se como meio de concentração de capital por poucos empreendedores, muitas vezes exógenos ao meio e excludente para os autóctones (LINDBERG; HAWKINS, 2002; BOO, 2002).

Referências metodológicas para o planejamento participativo do ecoturismo de base comunitária apontam etapas de diagnóstico, sistematização dos dados obtidos e formulação de ações condizentes com as demandas e com a realidade local. Tal processo demanda o autoconhecimento e o entendimento da comunidade sobre os aspectos do turismo em seu território, pois ao se pensar a atividade como alternativa econômica para uma localidade, deve-se entender o segmento como uma forma de valorização e conservação dos recursos naturais e culturais. Em se tratando da metodologia de planejamento turístico, o processo inicial abarca o inventário dos atrativos naturais, a estruturação turística e a promoção e comercialização do destino (BRASIL, 2007).

Neste processo os atores envolvidos deverão advir da sociedade civil organizada, terceiro setor, iniciativa privada, poder público e instituições de ensino, assim como representantes diretamente ligados à prestação de serviços turísticos. Dessa forma, a participação favorecerá a superação de conflitos e problemas no decorrer do processo de planejamento, bem como minimizará interferências negativas geradas a partir de desigualdades e diferenças étnicas, sociais, culturais, históricas, ambientais e econômicas (BRASIL, 2007).

\section{A RPPN Santuário do Caraça e seu entorno}

Pesquisas documentais afirmam que a primeira referência sobre o Caraça data de 1708, em mapas da Província de Minas Gerais (CARRATO, 1963). Registros historiográficos apontam a formação de arraiais na região, cujas origens remontam ao desbravamento do território brasileiro em busca de riquezas minerais pelos bandeirantes iniciado naquele período. Carrato (1963), Zico (1977) e Andrade (2000), entre outros, detalham a história religiosa do Caraça, desde os tempos de casa de hospedagem até as atividades do Colégio, composto por um projeto educativo rígido aplicado a segmentos sociais privilegiados. 
Desde a década de 1970 os ex-alunos e seus familiares iniciaram um processo de visitação ao Caraça que, gradativamente, foi se abrindo ao turismo. Pode-se observar que a instituição, efetivamente, gerida por padres, não estava preparada para enfrentar os desafios da gestão turística, mesmo que o segmento tenha se configurado como fonte essencial de sustentação econômica do santuário (PEREIRA; CARRIERI, 2005).

Em 1994, suas terras, equivalente a mais de 11 mil hectares, foram transformadas em RPPN, de âmbito federal, conforme a Lei SNUC (BRASIL, 2000; PBCM, 2007). Seu reconhecido complexo turístico é marcado pela exuberância da paisagem, da arquitetura, do patrimônio histórico-religioso, da biodiversidade que atraem, segundo relatos de 2009 da Coordenação Ambiental da Reserva, cerca de 60 mil visitantes anuais.

Sua vegetação composta por mata estacional semidecidual em diferentes estágios de sucessão ecológica, apresenta alternância de espécies pioneiras, secundárias e clímax. Tais formações florestais mesclam-se com grandes porções de cerradão, cuja imponência nos topos de morros é dada por diferentes espécies de candeia. $O$ clima úmido favorece a ocorrência de líquens e musgos, fundamentais bioindicadores de qualidade de ar. Não obstante sua importância ecológica, muitas espécies são exploradas inadequadamente, pois a sua valoração econômica propicia a extração como fonte de renda.

Em 2007 ocorreu a implantação da Sala Verde, por meio da parceira com o Ministério do Meio Ambiente e da PUC Minas. O objetivo era ampliar e aprimorar as iniciativas de educação ambiental, revigorando o espaço de cunho socioambiental do Centro de Visitantes da RPPN. As iniciativas de educação ambiental, também envolvem seus funcionários e, eventualmente, escolas e comunidades da região.

Em seu entorno, a RPPN convive, por um lado, com pressões da extração mineral intensa dos grandes empreendimentos e, por outro, uma diversidade sociocultural nas comunidades e nas cidades que a cercam. Os modos de vida típicos das comunidades, no entanto, demonstram, cada vez mais, os impactos das externalidades negativas da economia local e da urbanização crescente. As quatro comunidades selecionadas para a pesquisa são expressivas dessa afirmação (SANTOS, 2003; PEREIRA et al., 2010).

Para fins de análise, as localidades pesquisadas foram divididas em dois núcleos comunitários, a partir de sua proximidade geográfica e características socioambientais semelhantes (PEREIRA et al., 2009; SANTOS, 2003). O primeiro núcleo é composto por Santana do Morro e Sumidouro, comunidades localizadas "ao pé do Caraça", a $3 \mathrm{~km}$ da portaria principal da RPPN Santuário do Caraça. O outro núcleo reúne Conceição do Rio Acima e Galego, a $30 \mathrm{~km}$ distantes à entrada da referida UC (Figura 1). 


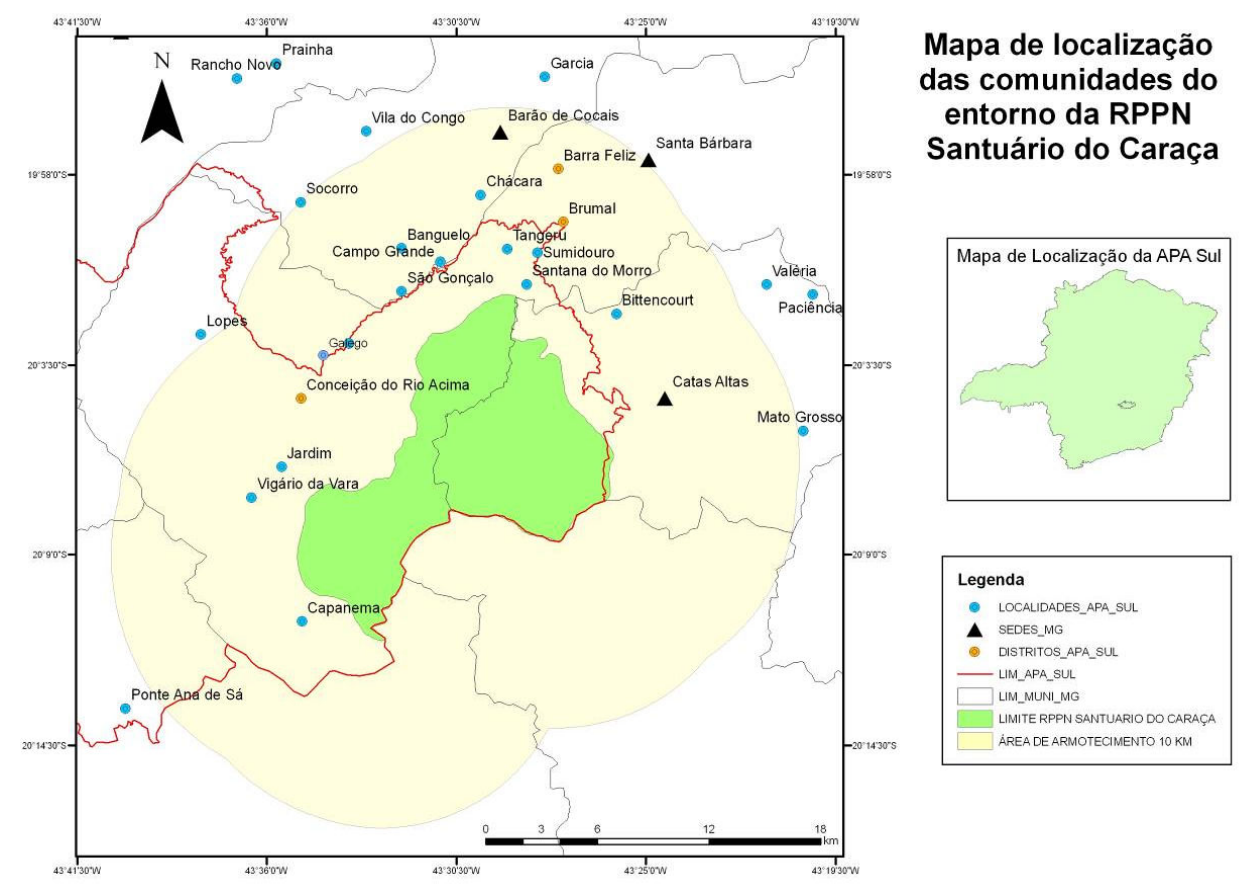

Figura 1: Mapa de localização das comunidades do entorno da RPPN Santuário do Caraça. Fonte: PEREIRA et al., 2010.

Santana do Morro e Sumidouro se caracterizam como comunidades rurais providas de equipamentos urbanos eficientes como meios de comunicação e transporte. É interessante salientar a migração populacional às cidades das gerações mais jovens e o avanço das tecnologias que descaracterizam a arquitetura e cultura tradicionais. Exemplo disso é o asfaltamento de ruas em Sumidouro, iniciado na década de 70 com a construção da rodovia Padre Jerônimo, um marco importante para potencializar o fluxo turístico à RPPN. Os habitantes mais antigos lamentam, no entanto, a perda de grande parte do secular patrimônio arquitetônico da comunidade, representado pela praça central envolta por palmeiras imperiais, onde se encontravam um chafariz e uma escadaria que levava à Igreja de São José. O intenso fluxo turístico ao Caraça possivelmente influenciou tais localidade em iniciativas na infraestrutura, na prestação de serviços e comércio, exemplificando-se a presença de pousadas, restaurantes e bares, mercearia e lojas com produtos locais artesanais e alimentícios, além de um pesque-e-pague, onde concentram moradores e pessoas vindas dos municípios circunvizinhos.

A população das duas comunidades totaliza em quase 600 pessoas, provendose de economia de subsistência, com atividades econômicas rurais de pequeno porte tais como o plantio da cana de açúcar, cafeicultura piscicultura (Figura 2). A empregabilidade da maioria dos moradores se dá em trabalhos permanentes e temporários na RPPN Santuário do Caraça, mas em diversos setores, seja na cozinha, monitoria, 
horticultura e vinicultura, recepção e atendimento aos visitantes, o que denota sua influência econômica nessas comunidades. Há, também, funcionários da prefeitura de Santa Bárbara e de empresas atuantes na região.


Figura 2: A) Praça central de Sumidouro, onde se identificam o chafariz e parte da escadaria de pedra que levava à Igreja de São José (esta ao fundo); B) Prática agrícola identificada em moradia de Sumidouro; C) Ribeirão Caraça, que divide Santana do Morro e Sumidouro; D)

Extração mineral de ouro em Santana do Morro.

O segundo núcleo comunitário, por sua vez, é composto por Conceição do Rio Acima e Galego, povoados rurais com habitações construídas nos arredores do Rio Conceição. $O$ acesso às comunidades ocorre por estradas vicinais que culminam nas vias pavimentadas do distrito.

A população total contabiliza quase 150 pessoas que, assim como verificado no outro núcleo, vivem da agricultura de subsistência, acrescentando-se ainda, maior dependência dos recursos naturais como a lenha, a pesca e a caça. A economia dessas localidades diversifica-se principalmente em atividades de silvicultura e apicultura. A infraestrutura turística se faz ainda incipiente. Não há pousadas; verificam-se, apenas, dois bares como pontos de socialização e lazer, atividades de silvicultura e api- 
cultura (Figura 3).
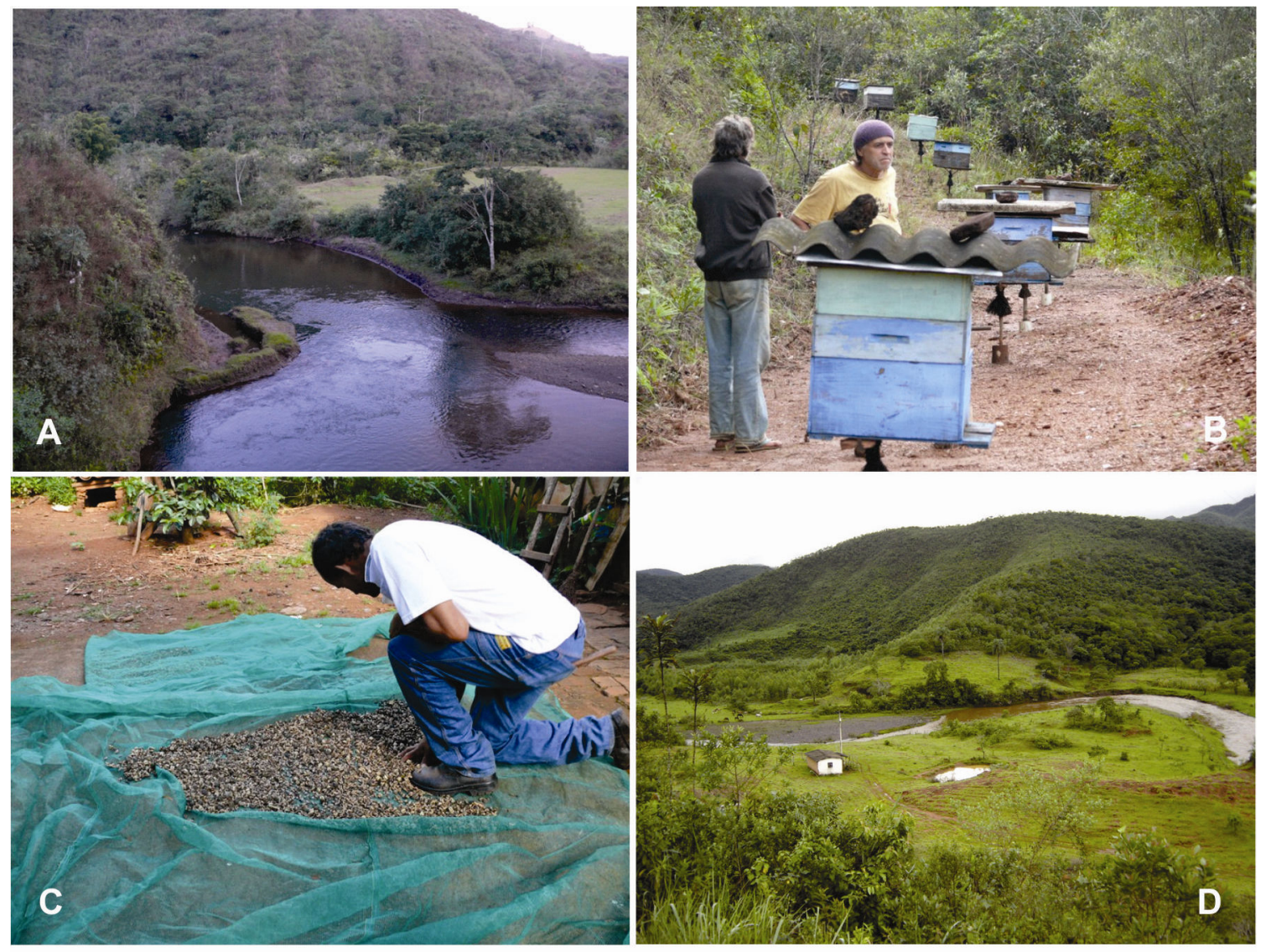

Figura 3: A) Os meandros do Rio Conceição; B) Prática em apicultura em Conceição do Rio Acima; C) Morador de Galego mostra colheita de feijão; D) Paisagem típica de Galego.

Importante característica social desses núcleos comunitários é a diversidade sociocultural marcada pela ocorrência constante de festividades e manifestações religiosas, o que revela valores e tradições atreladas a um modo de vida típico.

\section{As comunidades e o que sabem sobre si}

Considerando o DRP como técnica da pesquisa social que corrobora a noção de valor dos conhecimentos da comunidade, revelam-se, a seguir, elementos que desenham um cenário potencialmente apropriado para práticas de ecoturismo aliadas ao patrimônio cultural. Esse cenário apresenta significados de atrativos, construídos pela interpretação dos habitantes, conforme defendida por Goodey (2002). 
O processo da pesquisa, por vezes, estimulou a curiosidade da população, promovendo seu autoconhecimento, demonstrando o valor do que foi reafirmado por Murta e Goodey (2002) citando Freeman Tilden (1967), "através da interpretação, a compreensão; através da compreensão, a apreciação; e através da apreciação, a proteção" (p. 14).

Em relação ao patrimônio ambiental, as populações estão envoltas por extensa área preservada, com características já mencionadas. Identificam-se muitas trilhas sem sinalização e orientação aparentes, conhecidas pelos moradores mais antigos que ainda reconhecem características do típico modo de cercamento dos latifúndios de outrora.

Os saberes tradicionais se revelam na prática agrícola de gêneros alimentícios e medicinais, também fomentada pelas entidades extensionistas rurais e de representação comunitária. O plantio se dá principalmente para subsistência; demonstram sua criatividade com o uso de produtos culinários identificados em pratos típicos da comida mineira, bem como em invenções exóticas, onde se aproveitam alimentos e misturam-se temperos, readequando-se, assim, à disponibilidade periódica dos recursos. Estão presentes pratos como folha de assa-peixe à milanesa, brotos de bambu, munheca de samambaia, umbigo de banana, além das tradicionais receitas de angu de panela e couve refogada. As hortaliças e frutas são tradicionalmente livres de agrotóxicos. Existem importantes personagens com vastos conhecimentos culinários, adquiridos durante os ofícios no antigo Colégio do Caraça ou passados por gerações.

Os conhecimentos etnobotânicos relativos à identificação taxonômica de plantas e suas propriedades medicinais são recorrentes entre os mais idosos, cuja perpetuação se dá por meio da oralidade.

Vale destacar que o cultivo agrícola embora possibilite a geração de renda, não isenta os trabalhadores rurais das dificuldades enfrentadas para a venda dos produtos. Como resposta a essa demanda, a prefeitura de Santa Bárbara se comprometeu a comprá-los e encaminhá-los, posteriormente, à merenda escolar municipal. Tal acordo visou o incentivo ao desenvolvimento econômico regido pela forte tradição agrícola local, além de potencializar a nutrição dos estudantes. Embora isso, como parte do processo, as associações comunitárias interessadas tiveram que se cadastrar junto ao município, bem como apresentar o estatuto condizente com as normas do acordo. Nesse sentido, apenas uma associação de moradores pôde se beneficiar, ainda assim, mediante adequações documentais, revelando a carência da representação política dessas entidades.

Muitos produtores são estimulados pelas empresas de mineração e reflorestamento a plantar eucalipto com orientação técnica e garantia de compra do produto final, quando em época de poda; embora não seja muito rentável. Como outra alternativa de renda, há a comercialização da candeia, espécie abundante nos topos de morro de grande relevância econômica em função de suas propriedades medicinais e cosméticas. Seu manejo é restritivo e deve seguir um plano de manejo; embora nem to- 
dos os proprietários de terra tenha condições financeiras de arcar com tal instrumento de planejamento e gestão dos recursos naturais.

Durante caminhadas com moradores foi observado o plantio desordenado em áreas que, segundo a legislação ambiental, não permitem o uso dos recursos, como as adjacências de cursos d'água e nascentes, topos de morro e encostas com declividade específica, denominadas de Áreas de Preservação Permanente. Outra constatação aponta irregularidades fundiárias no que se refere à Reserva Legal, que consiste em preservar parte de uma propriedade rural produtiva, coibindo o uso dos seus recursos ambientais.

Segundo Primack e Rodrigues (2001), as leis de conservação regulamentam atividades que afetam diretamente as espécies e os ecossistemas, seja limitando a extração de produtos silvestres - caça, pesca - e produtos florestais, seja limitando o lançamento de resíduos oriundos da atividade produtiva, seja limitando-se o uso do solo, na designação de reservas privadas e unidades de conservação.

Pelos relatos dos entrevistados a fragmentação do habitat ocorre desde o início da povoação na região quando o desmatamento era ainda mais intensivo. Essa situação está se modificando, uma vez que, recentemente, a fiscalização tem sido mais aguerrida. Discussões sobre o cenário ambiental eram percebidas como geradoras de tensões sociais, marcadas pelo medo da denúncia sobre práticas locais remanescentes.

"O povo do mato tá de mãos amarradas. Eles sobrevivem é do quê, não é do mato? A terra é da gente, pagamos imposto e não tem como trabalhar. A gente precisa plantar uma horta, catar lenha, fazer pasto pra criar vaca. A fiscalização tá muito rigorosa. Nem os paus secos que ficam na margem do rio pode catar nem cortar. Eles falam que é pra apodrecer no local mesmo, pra adubar a terra. Eles querem que a gente aqui viva de gás? A gente precisa pegar lenha no mato pra colocar no fogão. O Plano de Manejo é muito caro, fica em uns $\mathrm{R} \$ 20.000,00$. Aí não compensa!" (morador de Conceição do Rio Aci$\mathrm{ma})$.

"No meu terreno eu planto muita coisa. Outro dia veio aí o meio ambiente [órgão ambiental fiscalizador] avaliar e viram que plantei eucalipto na reserva. A multa foi de $\mathrm{R} \$ 7.000,00$, mas não pude pagar até hoje. Isso aí [mostrando plantações de inhame-do-mato em cursos d'água] eles me falaram que não pode, mas eu como eu vou sobreviver, eu não vou plantar na minha própria terra?" (morador de Galego).

Os relatos também demonstram uma repressão desigual sobre moradores e empreendimentos minerários no que se refere ao uso de recursos ambientais:

"A mineração pode cortar pau que eles [órgão ambiental fiscalizador] não falam nada. A mineração pode, tem dinheiro. Então, uma vez pas- 
sou uns homens aí fiscalizando e perguntaram de quem era aquela região. Quando falaram que era da Vale eles disseram que não precisava de ir lá então." (morador de Conceição do Rio Acima).

É recorrente nas falas o desconhecimento da população sobre a legislação ambiental. Identifica-se um vácuo de informação sobre os usos corretos dos recursos naturais, inclusive para o extrativismo. A polícia ambiental, assim como o órgão fiscalizador, cumpre seu papel apenas na aplicação da lei, mas não contribui para formação dos indivíduos, educando-os ou esclarecendo-os sobre as normas e leis ambientais. Sua ação não é pautada pelo incentivo das práticas de uso sustentáveis oferecendo orientação e capacitação para o produtor rural, além de não oferecerem infraestrutura e recursos humanos adequados para o atendimento das demandas da população local.

Segundo as Deliberações Normativas do COPAM os cursos d'água obedecem a, que os institui como de Classe 1 e Especial, de acordo com a avaliação de parâmetros físicos, químicos e biológicos que fornecem indicadores de qualidade. Contradizendo tal realidade, moradores afirmam que os ribeirões recebem frequentemente resíduos domésticos, sem tratamento prévio. Vale ressaltar que Sumidouro é a única comunidade que possui uma Estação de Tratamento de Esgoto, embora esteja, atualmente, inoperante por deficiência técnica atribuída ao planejamento da obra. As demais localidades não possuem tratamento ou separação de seus resíduos, sendo que a destinação alterna-se entre queimadas, em fossa negra e em rede de esgoto lançada in natura ao rio.

O esgoto é, seguramente, um sério problema enfrentado pelas comunidades como indicam as polêmicas referentes ao seu lançamento nos cursos d'água. Os moradores de Galego argumentam sobre o desrespeito com os moradores a jusante do rio. Em Conceição do Rio Acima, eles concordam que a prática é ecologicamente errada e publicamente vergonhosa. Santana do Morro e Sumidouro relatam sobre as consequências desastrosas para o meio ambiente e à saúde humana.

De uma maneira geral, o saneamento básico é essencial nessas comunidades, mas discussões tramitam em torno de soluções contraditórias:

"Sobre o esgoto nós chegamos em duas coisas: Galego e Conceição
tem [rede] esgoto que cai diretamente no rio. Algumas pessoas dessas
duas comunidades têm fossa negra. Então o que a gente quer? Aca-
bar com [rede] esgoto e todo mundo volte à fossa de novo... O proble-
ma de Sumidouro, quer que arranje esgoto [amplie a rede de modo
que atinja mais pessoas]. Santana do Morro todo mundo é fossa, quer
fazer [rede de] esgoto." (Morador de Conceição do Rio Acima, com co-
mentários)

A fossa é considerada uma opção sustentável desde que utilizada com as devidas condições de instalação e funcionamento. Os moradores reconhecem, ainda, a 
existência de outras maneiras alternativas para disposição e tratamento do esgoto e que para se falar de conservação e proteção dos recursos naturais é necessário, no mínimo, que o entorno do habitat humano seja saneado e habitável, impondo, assim, a sua noção de saúde ambiental.

A sazonalidade dos alagamentos é fator relevante para as organizações sociais quando do excesso de chuvas, pelos impactos gerados na agricultura, na infraestrutura viária e sobre a moradia. Relatam dificuldades advindas da inundação, como a turbidez da água, barreamento de quintais e estradas, surgimento de minas de caráter temporário, além da perda da produção agrícola, as quais ocasionam impactos econômicos e sociais. Além disso, embora haja pontes sobre os ribeirões levando a Santana do Morro, a inacessibilidade das vias é também recorrente. Ainda que ocorra a abundância de água nessa estação, muitas casas sofrem impactos relativos à sua escassez, oriunda do entupimento da rede de distribuição e tubulação esburacada, permitindo a entrada de ar e vazamentos. Outro agravante relaciona-se aos reservatórios naturais de abastecimento, desprovidos de estruturas de proteção e manejo.

As comunidades constantemente responsabilizam os empreendimentos minerários pela diminuição de nascentes e cursos d'água, comparando tais atividades com suas práticas extrativistas:

"A diminuição da água, você pode me levar a mal, mas eu condeno mais as empresas mesmo. Por quê? Desmatar também não é certo. Mas a pessoa desmata, daí uns tempos volta a crescer a vegetação. Agora, quem explora a cabeceira da água, arranca o topo do morro, abre um buraco de 1000, 2000m pro chão abaixo. Então geralmente tá atingindo o lençol freático. Isso por causa da mineração (Morador de Galego).

Diante das atuais condições de disposição dos rejeitos de mineração, temem o rompimento das barragens localizadas no entorno das comunidades e criticam a ausência de recuperação dessas áreas degradadas, consideradas passivos ambientais. Além disso, aparentam insatisfação e sentimentos de impotência ao revelarem lembranças traumáticas ocorridas em um passado recente de vazamento de substâncias tóxicas nos rios.

"Antigamente o rio Conceição tinha muito peixe. Eu pescava bagre, piratininga, piabinha... Amanheceu um dia todo branco, com os peixes tudo boiando. Fomos seguindo o rio e descobrimos que era de lá da mineração de Capanema. Eles usam uma substância pra ver se tem minério, aí vazou pro rio." (morador de Galego) 
Sob a ótica sociocultural, vale destacar que as comunidades revelam uma diversidade tão importante quanto a diversidade física e biológica da região. Embora nesse aspecto sejam encontrados poucos registros históricos de ocupação das comunidades, a memória oral dos habitantes mais antigos registra o patrimônio cultural e a herança de suas riquezas sociais. É interessante ressaltar que diferentes enfoques histórico-cultuais demonstram a miscigenação de descendentes portugueses e africanos.

Segundo moradores, a caminhada ou vinda dos faiscadores (garimpeiros) era sempre acompanhada de imagens sacras devido aos perigos do percurso da descoberta de novas terras. A demonstração de fé e a importância dos valores religiosos culminavam com a construção de capelas no interior das matas para demarcação do território. Contam, assim, que as capelas das comunidades foram construídas e reformadas em devoção aos santos e em pagamento de promessas, seja por doenças, seja por fortuna alcançada:

"Meu bisavô, Joaquim Gonçalves Gouveia, era senhor de escravos. Ele prometeu à Nossa Senhora da Conceição que se a santa levasse a água de [rio] Brumadinho pra lavar o ouro, doaria metade do ouro encontrado para a obra da igreja." (moradora de Conceição do Rio Acima)".

As igrejas e capelas, algumas tombadas pelo patrimônio estadual, mantêm características seculares de grande relevância histórica.

"A Igreja era de madeira, cheia de caibo com barro por dentro. Em frente à Igreja tinha umas pilastras de pedra, mas tava caindo. Então as pessoas tiraram pra fazer o piso da Igreja. O teto era muito bonito. Tinha pintura com tinta de sangue de boi, urucum e nódoa de banana. Fizeram um estudo aí, parecia que era do mestre Ataíde, pelo estilo de pintura e material usado." (moradora de Conceição do Rio Acima).

Mais uma vez a oralidade se faz presente como indicadora dos conhecimentos histórico-culturais, complementando os poucos registros documentais e fotográficos. Lamentam a perda de muitas informações em função da fragilidade da memória.

Atualmente as construções religiosas e seus elementos internos são desprovidos de cuidados, demonstrando vicissitudes urgentes quanto à recuperação e à revitalização. As ações de restauração são onerosas, o que implica a busca de parcerias e articulação política. Sumidouro, por meio da associação de moradores, conseguiu o projeto de restauração da Igreja de São José, realizado por consultores financiados pela empresa de mineração de ouro atuante nas proximidades da comunidade. A cap- 
Ecoturismo, cultura e comunidades: reflexões sobre o entorno da RPPN Santuário do Caraça (MG).

tação de recursos para finalização do projeto ocorre em torno de ações comunitárias em festas e quermesses, além de articulação com a prefeitura e empreendimentos minerários locais.

Existem outras simbologias religiosas, exemplificadas pelos cruzeiros rústicos, feitos em madeira, com complementações rebuscadas, representando conhecimentos bíblicos da morte e paixão de Cristo por meio de objetos afincados. Suas significações são contadas com orgulho pelos moradores. É instigante comentar sobre alguns ritos envolvendo os cruzeiros que remetem apontamentos sobre estações climáticas. Em tempo de seca, a comunidade subia até o cruzeiro, carregando baldes ou latas de água sobre a cabeça. Uma criança, então, despejava a água no cruzeiro e todos rezavam, pedindo aos santos que trouxessem chuva.

No que tange às manifestações culturais, há uma intrínseca ligação com a religiosidade, como as festas em adoração aos santos padroeiros, procissões motorizadas ou a pé, levantamento de mastro e passagem da bandeira de santos, vinda de outras comunidades. Nessas ocasiões há queima de fogos, cavalgadas e encontros de cavaleiros, bandas de música tradicionais e atuais e bailes com som mecânico. Destacam-se a venda de produtos alimentícios e artesanais, dispostos em barraquinhas arranjadas com estrutura metálica ou de bambu.

O planejamento desses eventos é rigorosamente cumprido, principalmente por meio da iniciativa de pessoas ligadas à associação de moradores e pastorais. A mobilização acerca da obtenção de parcerias e arrecadação de recursos é marcada pela grande participação da população local.

Observa-se a dificuldade em transformar as festividades em atrações turísticas devido a comportamentos peculiares da comunidade. Os moradores são muito receptivos e paradoxalmente, discretos. A exposição e comercialização dos produtos locais são desvalorizadas frente à introdução de artefatos modernos e até mesmo utensílios estragados ou sujos. A divulgação dos eventos, ademais, é incipiente.

Os saberes artesanais e a criatividade se mostram presentes em todas as comunidades, adquiridos tradicionalmente ou por meio de cursos de capacitação de economia solidária, promovidos por instituições de extensão universitária, conforme trabalhos de Guimarães (2007). Demonstram uma variedade de técnicas quanto ao manejo do bambu e taquara, na construção de cestaria, tetos de alvenaria, armadilhas para caça e peneiras. Referindo-se aos bordados, evidenciam grande conhecimento e habilidade quanto ao manuseio de ponto-de-cruz, ponto-cheio, ponto-atrás, passa-fita, tricô e crochê. A produção de artefatos, como arranjos florais feitos com meia-calça e balões juninos feitos de garrafa PET, entre outros, utiliza os recursos disponíveis localmente e enfeita o interior das casas e festas comunitárias.

As falas apontam a presença de escravos que exploravam ouro nas minas. Tal constatação é esclarecida inclusive nas origens dos topônimos nas localidades próximas ao Caraça. Santana do Morro apresenta uma dubiedade toponímica, também conhecida como "Arranca Toco", como elucidam: 
"Um escravo, que apanhava de seu senhor, estava amarrado em um toco, afincado no rio, e gritava 'Arranca o Toco!'” (morador de Santana do Morro).

Sumidouro, por sua vez, mostra uma diversidade de explicações referentes ao seu topônimo:

\begin{abstract}
"Os garimpeiros iam a lugares que pareciam brotar ouro. Mas quando procuravam, o ouro tinha sumido. Então ficou o nome de Sumidouro, local onde sumia o ouro." (moradora da Sumidouro).
\end{abstract}

"Conta que Sumidouro é a junção de 'sumo do ouro', o que significa o ouro de melhor qualidade." (morador de Sumidouro).

Essa comunidade traz, em sua memória, fatos da convivência com os negros que, após o garimpo, se alimentavam da feijoada negreira (feijão e porções suínas não consumidas pelos senhores, como pés, orelhas, focinhos, etc.) colocadas em cocho ou gamela, dispostos nas janelas das casas.

Destacam-se antigas cavas de minas, atualmente desativadas, mas que instigam sentimentos de curiosidade quanto à sua história e usos. Tais locais encontramse em áreas particulares (ora de moradores, ora de empresas mineradoras), cuja condição atual revela abandono e riscos de desabamento.

Há resquícios de moinhos, muros e de antigas moradias, como a casa da última escrava de Conceição do Rio Acima, construída com paredes de pedra e colunas de madeira, além de indícios de uma senzala, no porão de outra habitação, com assoalho de madeira. Identificam-se essas características, também, em outras moradias de Galego. Essas construções são reutilizadas na composição das atuais casas, acarretando em degradação e descaracterização do estilo original.

"Os escravos bateavam o ouro no rio e sobrava aquele monte de pedra, de cascalho. Tinham que arrumar alguma função e então construíram os muros." (moradora de Conceição do Rio Acima).

Ruínas de pedra foram encontradas em meio à estrutura arquitetônica atual e no interior de matas. As pedras soltas, interpretadas como vestígios do garimpo, e designação curiosa dada a um morro, este, denominado "Morro do Vintém", onde foi encontrado o maior vintém de ouro da região.

Com a decadência do ciclo do ouro, a mineração de ferro foi apontada em Conceição do Rio Acima como alternativa econômica. Os moradores relatam ter trabalha- 
do em uma antiga fábrica de ferramentas nas adjacências da comunidade, utilizando o ferro como matéria-prima. Hoje restam apenas suas ruínas.

A relação com a RPPN Santuário do Caraça apresenta diferenças entre as comunidades. Pela proximidade com a reserva, Santana do Morro e Sumidouro carregam valores e tradições advindos do santuário religioso, cuja empatia com os padres e missionários se faz marcante. Apresentam, igualmente, uma dependência simbiótica quanto à empregabilidade, conforme diagnosticado por Santos (2003). Em Galego e Conceição do Rio Acima a referência maior é o complexo arquitetônico-histórico representado pela Igreja Nossa Senhora Mãe dos Homens. Em geral, as populações têm a visão de um local distante e isolado.

Uma moradora idosa de Galego, que trabalhou na cozinha do Caraça, no Colégio e na Fazenda do Engenho, relata sua história associada ao Santuário:

\begin{abstract}
"Quando eu tinha 1 ano e 5 meses, me perdi no mato, enquanto meus pais foram trabalhar. No desespero, minha mãe prometeu à Nossa Senhora Mãe dos Homens que se me achasse, quando eu ficasse maiorzinha, iria trabalhar no Caraça, pra servir à santa. Com 12 anos comecei a ajudar os padres lá no Caraça e acabei trabalhando 28 anos. As orações tudo que eu sei aprendi lá. (...) Eu tava lá no incêndio. Fui eu que avisei os padres que tava pegando fogo. Era de madrugada e eles acharam que eu tava sonhando, num acreditaram. Vi que tava saindo fumaça, mas eles pensaram que era a garoinha, que todo dia desce da serra." (moradora de Galego).
\end{abstract}

\title{
Conclusão
}

Após a contextualização temática e das comunidades do entorno da RPPN Santuário do Caraça pode-se concluir sobre o potencial de atrativos culturais, ambientais e turísticos da região. As histórias, as ruínas, a natureza, a paisagem e o seu povo são elementos que compõem um cenário positivo para se contrapor às pressões do desenvolvimento econômico, da extração mineral, da especulação imobiliária, das restrições ambientais. No entanto, os fatores alicientes nas ofertas de empregos na indústria contemporânea tendem a se tornar preponderantes nas decisões da população em detrimento da opção pela vida no campo.

É nesse sentido que se faz pertinente a proposição de transformar os esforços da rede socioambiental local, em um fórum para o debate e a construção de alternativas para a preservação cultural e a consolidação do ecoturismo como fontes complementares para revigorar a economia local, criando uma perspectiva de diversificação de atividades geradoras de renda.

A composição da rede entre membros das comunidades, atores da sociedade 
civil, da iniciativa privada e de entidades públicas, pode promover laços com outros atores e instituições capazes contribuir para o fortalecimento dos processos de formatação de projetos a respeito dessas iniciativas. Dentre as necessidades básicas para se compor esse quadro favorável, a pesquisa permitiu a identificação prioritária da educação e da qualificação da população para lidar com os conhecimentos necessários à prática do ecoturismo, especialmente a partir de metodologias participativas, que contemplem a valorização dos saberes locais, de sua cultura, de seu patrimônio material e imaterial.

Em síntese, o caráter híbrido da rede local pode garantir condições para que ela se transforme num locus privilegiado de diálogo e articulação sobre o planejamento turístico de base comunitária.

\section{Referências Bibliográficas}

ANDRADE, M. G. A educação exilada: Colégio do Caraça. Belo Horizonte: Autêntica, 2000. 216p.

AKEHURST, G. Estratégia de desenvolvimento turístico orientado para a comunidade - Kalisz, Polônia. In: TYLER, D.; GUERRIER, Y.; ROBERTSON, M. Gestão de turismo municipal: teoria e prática de turismo nos centros urbanos. São Paulo: Futura, 2001.

BEGOSSI, A. HANAZAKI, N.; PERONI, N.; SILVANO, R.A.N. Estudos de ecologia humana e etnobiologia: uma revisão sobre usos e conservação. In: ROCHA, C. F. D.; BERGALHO, H.G.; SLUYS, M.V.; ALVES, M.A.S. Biologia da conservação: essências. São Carlos: RiMa, p. 537-562, 2006.

BENI, M. C. Análise Estrutural do Turismo. São Paulo: Editora Senac, 2004. 513p.

BOO, E. O planejamento ecoturístico para áreas protegidas. In: LINDBERG, K.; HAWKINGS, R. E. Ecoturismo: um guia para planejamento e gestão. $4^{a}$ ed. São Paulo: SENAC, p. 31-57, 2002.

BRANDOM, K. Etapas básicas para incentivar a participação local em projetos de turismo voltado para a natureza. In: LINDBERG, K.; HAWKINGS, R. E. Ecoturismo: um guia para planejamento e gestão. $4^{\mathrm{a}}$ ed. São Paulo: SENAC, p. 223-252, 2002.

BRASIL. Decreto 6.040, Art. $3^{\circ}$, de 07 de fevereiro de 2007. Institui a Política Nacional de Desenvolvimento Sustentável dos Povos e Comunidades Tradicionais. Diário Oficial da União, Brasília, 07 fev. 2007. 
Ecoturismo, cultura e comunidades: reflexões sobre o entorno da RPPN Santuário do Caraça (MG).

BRASIL. Lei 9.985, de 18 de julho 2000. Regulamenta o art. 225, § 1o, incisos I, II, III e VII da Constituição Federal, Institui o Sistema Nacional de Unidades de Conservação da Natureza e dá outras providências. Diário Oficial da União, Brasília, 30 mar. 2008.

BROSE, M. (org.). Metodologia participativa: uma introdução a 29 instrumentos. Porto Alegre: Tomo Editorial, 2001. 306p.

BUARQUE, S. C. Metodologia de planejamento do desenvolvimento local e municipal sustentável. Projeto de Cooperação Técnica INCRA/IICA; PCT - INCRA/IICA. Brasília, 1999.

CALDAS, E. L.; VAZ, J. C.; MARTINS, R. D. Desenvolvimento local: concepção, avanços e desafios. São Paulo: Instituto Pólis, 2005. Disponível em: <http:// www.polis.org.br/download/53.ppt>. Acesso em: 07 maio 2009.

CARRATO, J. F. As minas gerais e os Primórdios do Caraça. São Paulo: Companhia Editora Nacional, coleção Brasiliana, v. 317, 1963. 463p.

CARVALHO, J. M. Cidadania no Brasil: o longo caminho. $6^{\text {a }}$ ed. Rio de Janeiro: Civilização Brasileira, 2004.

DOWBOR, L. O desenvolvimento local e a racionalidade econômica. Rede de Tecnologia Social RTS. 2006. Disponível em: <http://www.rts.org.br/artigos/artigos2006/o-desenvolvimento-local-e-aracionalidade-economica/s. Acesso em: 18 out. 2009.

GOODEY, B. Interpretação e comunidade local. In: MURTA, S. M.; ALBANO, C. (orgs.). Interpretar o patrimônio: um exercício do olhar. Belo Horizonte: UFMG; Território Brasilis, p. 47-57, 2002.

GUIMARÃES, H. W. M. Capacitação e educação para o desenvolvimento sustentável de pequenos produtores, negociantes e artesãos da baixada caracense: $2^{\mathrm{a}}$ fase. Relatório final de Projeto de Extensão da PUC Minas, 2007.

LINDBERG, K.; HAWKINGS, R. E. Ecoturismo: um guia para planejamento e gestão. $4^{a}$ ed. São Paulo: SENAC, 2002. 292p.

MINAYO, M. C. de S. (org.) Pesquisa social - Teoria, método e criatividade. $23^{a}$ ed. Petrópolis: Vozes, 2004. 80p.

MURTA, S. M.; GOODEY, B. Interpretação do patrimônio para visitantes: um quadro conceitual. In: MURTA, S. M; ALBANO, C. (orgs.). Interpretar o patrimônio: um exercício do olhar. Belo Horizonte: UFMG; Território Brasilis, p. 13-46, 2002. 
Plastino, M.R.; Pereira, D.C.; Maia, M.G.M.; Lopes, D.A.

PEREIRA, D. de C. et al. Projeto estruturante da Rede de Extensão Socioambiental em Regiões Mínero-metalúrgicas: a APA SUL, seu mosaico de unidades de conservação e as comunidades do entorno. Belo Horizonte: PUC Minas/FAPEMIG, 2010. (Relatório Técnico-Científico de Pesquisa - Projeto CRA 2350/09). 378p.

PEREIRA, D. de C.; CARRIERI, A. de P. Espaço religioso e espaço turístico: significações culturais e ambiguidades no Santuário do Caraça/MG. O\&S. Salvador, v. 12, n. 34, p. 31-50, 2005.

PRIMACK, R. B.; RODRIGUES, E. Biologia da Conservação. Londrina: Planta, 2001. 328p.

PROVÍNCIA BRASILEIRA DA CONGREGAÇÃO DA MISSÃO - PBCM. Plano de Ação da PBCM para o Caraça 2007. (Documento Interno).

RITS. 3a Expo Brasil Desenvolvimento Local. São Paulo: RITS, 2004.

ROCHA, J. C. A reinvenção solidária e participativa da universidade: um estudo sobre redes de extensão universitária no Brasil. 2006. Tese (Doutorado em Educação) - Faculdade de Educação - Universidade Federal da Bahia, Salvador, 2006.

ROCHA, R. M. G. Extensão universitária: momento de aplicação do conhecimento e de intercâmbio de saberes na relação universidade sociedade? In: THIOLLENT, M. et al. (orgs.) Extensão universitária: conceitos, métodos e práticas. Rio de Janeiro: UFRJ, 2003.

RUSSO, C. R. Comunidades tradicionais e preservação cultural por meio do ecoturismo. In: MENDONÇA, R.; NEIMAN, Z. (org.). Ecoturismo no Brasil. Barueri: Manole, 2005.

SANTOS, B. S. (org.). A globalização e as ciências sociais. São Paulo: Cortez, 2005. 572p.

SANTOS, S. N. Comunidades do entorno da RPPN do Caraça: caracterização sócio-ambiental. Projeto de pesquisa - Pontifícia Universidade Católica de Minas Gerais, Programa de Pós-Graduação em Zoologia de Vertebrados (2003). Projeto FIP 14-P/2002. (mimeo)

THIOLLENT, M. Metodologia da Pesquisa-ação. 13a ed. São Paulo: Cortez, 2004. $108 p$.

TORO, J. B.; WERNECK, N. M. D. Mobilização Social: um modo de construir a democracia e a participação. Belo Horizonte: Autêntica, 2005. 104p.

ZICO, J. T. Caraça: Peregrinação, Cultura e Turismo, 1770 - 1975. $2^{\mathrm{a}}$ ed. Contagem: Líttera Maciel, 1977. 270p. 


\section{NOTA}

${ }^{1}$ Projeto Estruturante da Rede de Extensão Socioambiental em Regiões Mínerometalúrgicas: a APA Sul, seu mosaico de unidades de conservação e as comunidades do entorno, do qual fazem parte as autoras deste artigo. (Convênio PUC Minas/ FAPEMIG) (PEREIRA et al., 2010).

\section{Agradecimentos}

Agradecemos o apoio da Secretaria de Estado de Ciência, Tecnologia e Ensino Superior de Minas Gerais, por intermédio do Pólo de Excelência Mineral e Metalúrgico, juntamente com a PUC Minas pela Pró-reitoria de Extensão. Agradecemos também o fomento da FAPEMIG e, em especial, o apoio da RPPN Santuário do Caraça, suas comunidades adjacentes e as entidades locais comunitárias, extensionistas e de desenvolvimento socioeconômico.

Marina Ramos Plastino: Bolsista de Iniciação Cientifica - PUC - Minas.

Email: entretanto_br@yahoo.com.br

Link para currículo Lattes: http://lattes.cnpq.br/8679878706859693

Denise de Castro Pereira: Professora adjunta da PUC - Minas.

Email: dpereira@pucminas.br

Link para currículo Lattes: http://lattes.cnpq.br/2321560097092899

Marlete da Glória Martins Maia: Bolsista de Iniciação Cientifica - PUC - Minas.

Email: gloritamaia@yahoo.com.br

Link para currículo Lattes: http://lattes.cnpq.br/8712541392683395

Danielle Alves Lopes: Graduanda - PUC - Minas.

Email: daniellealveslopes@hotmail.com.br

Link para currículo Lattes: http://lattes.cnpq.br/4544556971978635

Data de submissão: 01 de novembro 2009.

Data do aceite: 09 de abril de 2010. 